\title{
MORPHOMETRIC MEASUREMENTS OF SACRAL HIATUS IN SOUTH INDIAN DRY HUMAN SACRA FOR SAFE CAUDAL EPIDURAL BLOCK
}

\section{Susie Jeyalyn David}

Assistant Professor, Department of Anatomy, Sree Mookambika Institute of Medical Sciences, Kulasekharam, Kanyakumari District, Tamilnadu, India.

\section{ABSTRACT}

Introduction: The sacral hiatus is located on the posterior aspect of the lower end of the sacrum, where the extradural space ends. The clinically significant features of the posterior surface of the sacrum are the triangular or inverted ' $U$ ' shape sacral hiatus and the sacral cornua.The knowledge of Anatomical variations of Sacral hiatus is significant while administration of Caudal Epidural Anaesthesia and it may help to improve its success rate.

Aim: The purpose of this study is to recognize anatomical variations and additional landmarks of sacral hiatus in cases where the sacral cornua could not be identified and to assess proportions that may magnify the location of the apex of the sacral hiatus and thus to find a practical solution for Caudal epidural block (CEB).

Materials and methods: The present study was conducted on unknown sixty one complete and undamaged adult, dry sacral bones. The material was of undetermined age and gender. Anatomical measurements was carried out on these bones using a vernier calliper to the accurate of $0.1 \mathrm{~mm}$.

Results: Variations in the shapes and their percentages of Sacral hiatus were observed namely Elongated, Inverted $U$, Irregular, Inverted V, Dumbbell and Bifid along with their distances and Angles of use in detecting the Apex were measured. The location of Apex of Sacral hiatus was found at varying levels from upper end of S2 to lower part of S5 vertebrae. Also we measured the angles between the margins of the triangle formed by the two superolateral sacral crests and the sacral hiatus. Our measurements reveal this to be an equilateral triangle.

Conclusion: This knowledge of variations in Human sacral hiatus provides a safe caudal epidural block before surgery and complications can be avoided.We believe that the equilateral character of the sacral triangle formed connecting the two posterior superior iliac spines and the apex of the sacral hiatus will be practical advantage to the clinician in ascertaining the location of the sacral hiatus during CEB.

KEY WORDS: Sarum, Sacral Hiatus, Sacral Apex, Caudal Epidural Anaesthesia.

Address for Correspondence: Susie Jeyalyn David, Assistant Professor, Department of Anatomy, Sree Mookambika Institute of Medical Sciences, Kulasekharam -629 161, Kanyakumari District, Tamilnadu, India. Ph: +91 9443622530. E-Mail: drsuslyn@gmail.com

Access this Article online

Quick Response code

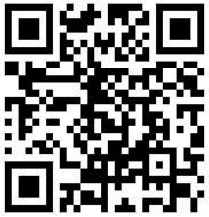

DOI: $10.16965 /$ ijar.2019.254

Journal Information

International Journal of Anatomy and Research

ICV for 2016 ISSN (E) 2321-4287 | ISSN (P) 2321-8967

90.30

https://www.ijmhr.org/ijar.htm

DOI-Prefix: https://dx.doi.org/10.16965/ijar

Article Information

Received: 15 Jun 2019

Peer Review: 17 Jun 2019

Revised: None
Accepted: 05 Aug 2019

Published (O): 05 Sep 2019

Published (P): 05 Sep 2019

\section{INTRODUCTION}

The sacral hiatus is located on the posterior aspect of the lower end of the sacrum, where the extradural space ends. The sacral hiatus lies about $5 \mathrm{cms}$ above the tip of the coccyx and underneath the skin of the natal cleft . The clinically significant features of the posterior surface of the sacrum are the triangular or inverted ' $U$ ' shape sacral hiatus and the sacral cornua.

In the midline the laminae of the $5^{\text {th }}$ sacral vertebra and occasionally those of the $4^{\text {th }}$ sacral vertebra also fail to meet thus forming the sacral hiatus and the shape and size of the 
hiatus is based upon on the number of laminae which fail to fuse posteriorly in the midline and its depth differs, depending on how much the spinous process as well as the laminae of S4 are present. The sacral hiatus accomodates lower sacral \& coccygeal nerve roots, filum terminale externa as well as fibro fatty tissue.

The sacral hiatus in the living persons, is covered by the sacrococcygeal ligament, which is penetrated by the filum terminale. The epidural space of the sacral canal deep to the ligament is filled with fatty connective tissue.

At the sides of the sacral cornua the inferior articular processes of the $5^{\text {th }}$ sacral vertebra jut downwards and are a valuable guide in locating the sacral hiatus[1].

With the patient lying prone over a pelvic pillow or in the lateral position, the sacral hiatus is recognized by palpation of the cornua of the sacrum. Roughly $5 \mathrm{~cm}$ up above the tip of the coccyx these are identified at the upper edge of the natal cleft.

The spinous process of S2 lies at the midway of a line drawn connecting the posterior superior iliac spines, which is indicated by the skin dimples formed by the attachment of deep fascia and skin to the posterior superior iliac spines. This level shows the inferior stretch of the subarachnoid space (lumbar cistern).

The sacral hiatus may be located alternatively, by establishing an equilateral triangle based on a line connecting the posterior superior iliac spines and the lower apex of this triangle lie over the sacral hiatus. The sacral triangle is established by the lines connecting the two posterior superior iliac spines and the upper part of the inter gluteal cleft in between the buttocks. The sacral triangle defining the sacrum is an usual area of pain which results from low back sprains. The sacral hiatus can be palpated at the lower end of the sacrum situated in the upper part of the intergluteal cleft[2].

The epidural space is seen between the spinal dura as well as the wall of the vertebral canal. It accomodates epidural fat and a venous plexus. Access to the epidural space is needed for the administration of analgesic and anaesthetic drugs \& for endoscopy. For analgesic injections the caudal route is mainly used. The route of access to the caudal epidural space is through the sacral hiatus. Therefore the caudal epidural space is approached below the level of the termination of the dural sac and its contained CSF, which usually extends upto the level of the $2^{\text {nd }}$ sacral segment[3].

Sacral hiatus has been employed in obstetrics for administration of epidural anaesthesia[4] (Edward et al) and for treatment \& diagnosis in orthopaedic practice [5] (Sekiguchi M et al). In obstetrics caudal anaesthesia is utilized to block pain fibres from the cervix of the uterus and also to anaesthetize the perineum. Caudal anaesthesia is utilized in surgeries in the sacral region which includes anorectal surgery and culdoscopy. The advantage is that, when administered by this technique, the anaesthetic does not affect the infant[3].

Further, trans-sacral thecaloscopy requires a thorough familiarity of morphometric parameters of $\mathrm{SH}$ for the atraumatic use of flexible endoscopes [6].

The purpose of this study is to recognize anatomical variations and additional landmarks of sacral hiatus in cases where the sacral cornua could not be identified and to assess proportions that may magnify the location of the apex of the sacral hiatus and thus to find a practical solution for Caudal epidural block (CEB). We determined measurements and the anatomical borders of the sacral hiatus on dry sacral bones that might be utilised during Caudal epidural block procedures.

\section{MATERIALS AND METHODS}

The present study was conducted in the Department of Anatomy, Kasturba Medical College, Mangalore, Karnataka, INDIA on unknown sixty one complete and undamaged adult, dry sacral bones. Out of them, one sacrum was excluded since it had total posterior closure defect. The material was of undetermined age and gender. Anatomical measurements was carried out on these bones using a vernier calliper to the accurate of $0.1 \mathrm{~mm}$.

On the surface of the body of a subject the posterior superior iliac spines which impose on the superolateral crests of the sacrum are easily palpable, and our measurements were accomplished on dry sacral bones, the latter points 
being utilized as landmarks in the measurements.

As the dural sac terminates around the level of S2, the distances from the apex, and the base of the sacral hiatus to the level of S2 foramina were also measured.

Fourteen direct morphometric measurements of importance for Caudal epidural block, relating to the sacral vertebra and hiatus were reached.

Fig. 1: Elongated sacral hiatus.

Fig. 2: Irregular shaped sacral hiatus.

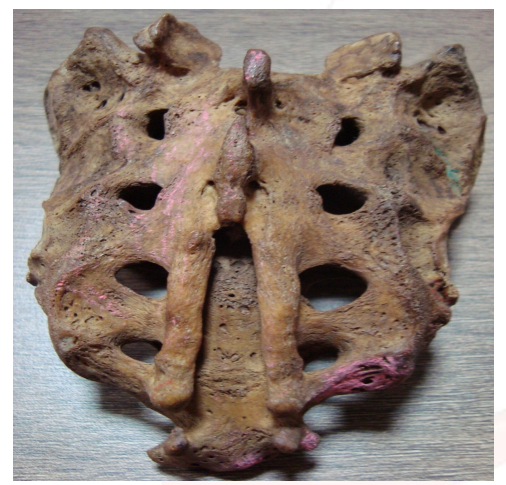

Fig. 3: Inverted U

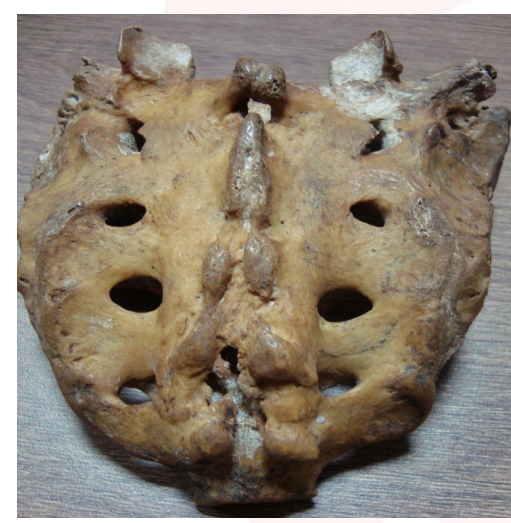

shaped sacral hiatus.

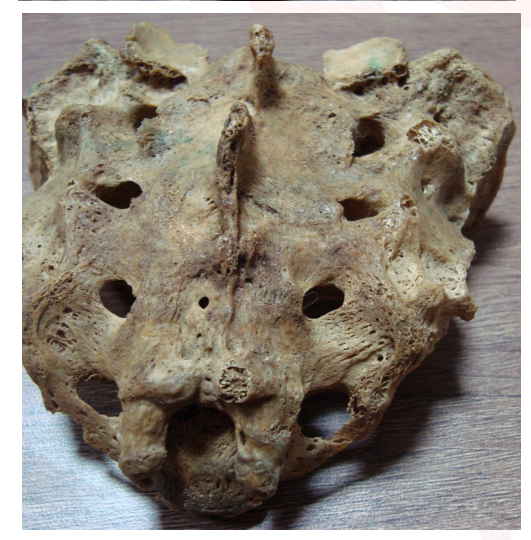

Fig. 4: Inverted V shaped sacral hiatus.
Fig. 5: Bifid sacral hiatus.

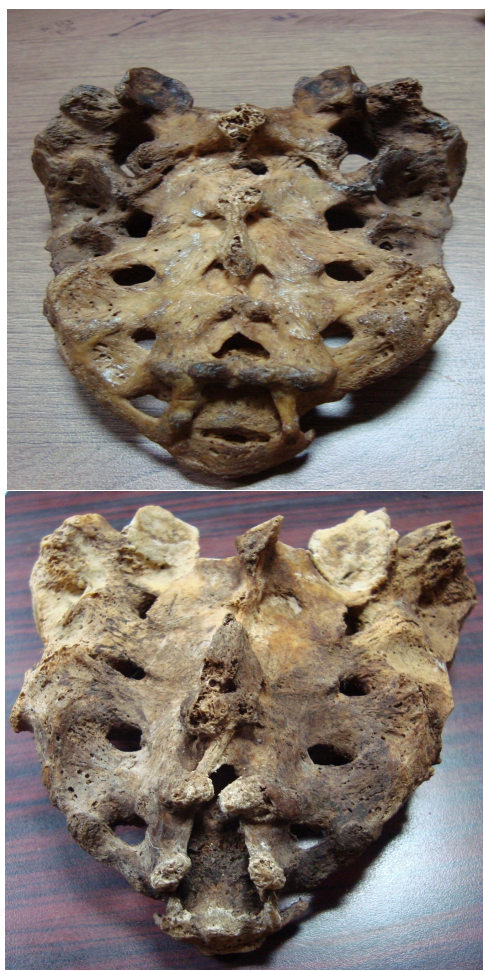

Fig. 7: Posterior surface of sacrum showing morphometric parameters:

(b)Transverse width at base ; (c)Length of Hiatus; (d)Distance from Apex to S2 foramina ; (e)Length of Hiatus+ Distance from Apex to S2 foramina ; (f)Distance from upper border of S1 to Apex of sacral hiatus

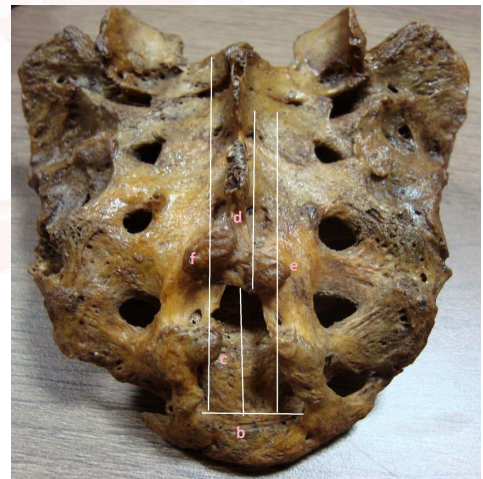

Fig. 8: Posterior surface of sacrum showing morphometric parameters forming equilateral triangle: (A) Base of the triangle (Distance between two superolateral crests)

(B) Distance between right superolateral sacral crest \& sacral apex

(C) Distance between left superolateral sacral crest \& sacral apex

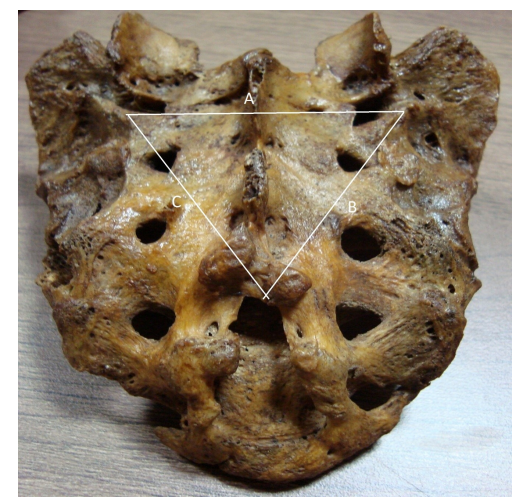


Statistical Analysis: The statistical analysis and interpretations were performed by the statistical package namely IBM statistics-20.

\section{RESULTS AND TABLES}

Table 1: Shape of sacral hiatus $(n=60)$.

\begin{tabular}{|c|c|c|c|}
\hline S.No & Shape & Frequency & Percent \\
\hline $\mathbf{1}$ & Elongated & 20 & $33.30 \%$ \\
\hline $\mathbf{2}$ & Irregular & 14 & $23.30 \%$ \\
\hline $\mathbf{3}$ & Inverted U & 14 & $23.30 \%$ \\
\hline $\mathbf{4}$ & Inverted V & 8 & $13.30 \%$ \\
\hline $\mathbf{5}$ & Bifid & 2 & $3.30 \%$ \\
\hline $\mathbf{6}$ & Dumbbell & $\mathbf{2}$ & $3.30 \%$ \\
\hline
\end{tabular}

The above table shows high percentages of elongated shape of sacral hiatus (33.3\%) followed by $23.3 \%$ irregular and inverted $U$ shape of same percentage, and the least was of $3.3 \%$ of bifid and dumbbell.

Table 2: Location of apex of sacral hiatus in relation to the level of sacral vertebra.

\begin{tabular}{|c|c|c|c|}
\hline S.No & $\begin{array}{c}\text { Location Of } \\
\text { Apex }\end{array}$ & Frequency & Percent \\
\hline $\mathbf{1}$ & S4 & 31 & $51.70 \%$ \\
\hline $\mathbf{2}$ & S3 & 20 & $33.30 \%$ \\
\hline $\mathbf{3}$ & S5 & 7 & $11.70 \%$ \\
\hline $\mathbf{4}$ & S2 & 2 & $3.30 \%$ \\
\hline
\end{tabular}

The above table shows the level of sacral hiatus in $51.7 \%$ at the level of $\$ 4$,followed by $33.3 \%$ at the level of S3 and there were only 3.3\% at the level of S2.

Table 3: Location of base of sacral hiatus in relation to level of sacral vertebra.

\begin{tabular}{|c|c|c|c|}
\hline S.No & $\begin{array}{c}\text { Location Of } \\
\text { Base }\end{array}$ & Frequency & Percent \\
\hline $\mathbf{1}$ & S5 & 40 & $66.70 \%$ \\
\hline $\mathbf{2}$ & Coccyx & 20 & $33.30 \%$ \\
\hline
\end{tabular}

Table -3 shows more of sacral base at the level of S5 in $66.7 \%$, while rest showed at the level of Coccyx (33.3\%)
Table 4: Antero posterior diameter of sacral canal at the level of apex of sacral hiatus.

\begin{tabular}{|c|c|c|c|}
\hline S.No & Diameter & Frequency & Percent \\
\hline $\mathbf{1}$ & $0-3 \mathrm{~mm}$ & 2 & $3.33 \%$ \\
\hline $\mathbf{2}$ & $4-6 \mathrm{~mm}$ & 31 & $51.66 \%$ \\
\hline $\mathbf{3}$ & $7-9 \mathrm{~mm}$ & 27 & $45 \%$ \\
\hline
\end{tabular}

AP diameter of sacral canal at the sacral hiatus apex was between the range of $4-6 \mathrm{~mm}$ in $51.66 \%$ followed by $7-9 \mathrm{~mm}$ in $45 \%$ and $0-3 \mathrm{~mm}$ in $3.3 \%$. Table 5: Distance between the sacral cornua (transverse width) at the base of sacral hiatus.

\begin{tabular}{|c|c|c|c|}
\hline S.No & Distance & Frequency & Percent \\
\hline $\mathbf{1}$ & $0-5 \mathrm{~mm}$ & Nil & Nil \\
\hline $\mathbf{2}$ & $6-10 \mathrm{~mm}$ & 2 & $3.33 \%$ \\
\hline $\mathbf{3}$ & $11-15 \mathrm{~mm}$ & 24 & $40 \%$ \\
\hline 4 & $16-20 \mathrm{~mm}$ & 31 & $51.66 \%$ \\
\hline $\mathbf{5}$ & Above $20 \mathrm{~mm}$ & 3 & $5 \%$ \\
\hline
\end{tabular}

The maximum distance between the sacral cornua was seen in $51.66 \%$ which had a distance of $16-20 \mathrm{~mm}$ and $11-15 \mathrm{~mm}$ in $40 \%$ and above $20 \mathrm{~mm}$ in $5 \%$. The other measurement namely $6-10 \mathrm{~mm}$ in $3.33 \%$ and there were no sacra cornua having less than $5 \mathrm{~mm}$.

Table 6: Length of the sacral hiatus from apex to midpoint of base.

\begin{tabular}{|c|c|c|c|}
\hline S.No & Length & Frequency & Percent \\
\hline $\mathbf{1}$ & $0-10 \mathrm{~mm}$ & 3 & $5 \%$ \\
\hline $\mathbf{2}$ & $11-20 \mathrm{~mm}$ & 11 & $18.33 \%$ \\
\hline $\mathbf{3}$ & $21-30 \mathrm{~mm}$ & 18 & $30 \%$ \\
\hline $\mathbf{4}$ & $31-40 \mathrm{~mm}$ & 17 & $28.33 \%$ \\
\hline $\mathbf{5}$ & $41-50 \mathrm{~mm}$ & 9 & $15 \%$ \\
\hline $\mathbf{6}$ & Above $51 \mathrm{~mm}$ & 2 & $3.33 \%$ \\
\hline
\end{tabular}

The maximum length between the midpoint of the base of the sacrum to the apex of the sacral hiatus was seen maximum in $3.33 \%(51 \mathrm{~mm}$ above) followed by $41-50 \mathrm{~mm}$ in $15 \%, 31-40 \mathrm{~mm}$ in $28.33 \%$ and the least was seen in $5 \%$ (0-10mm).

Table 7: The anatomical measurements are given in the following table:

\begin{tabular}{|c|c|c|c|c|c|c|c|c|}
\hline \multirow{2}{*}{ Parameters } & \multirow{2}{*}{$\mathbf{N}$} & \multirow{2}{*}{ Mean } & \multirow{2}{*}{$\begin{array}{c}\text { Std. } \\
\text { Deviation }\end{array}$} & \multirow{2}{*}{ Std.error } & \multicolumn{2}{|c|}{$\begin{array}{c}95 \% \text { confidence interval } \\
\text { for Mean }\end{array}$} & \multirow[t]{2}{*}{ Minimum } & \multirow{2}{*}{ Maximum } \\
\hline & & & & & $\begin{array}{l}\text { Lower } \\
\text { bound }\end{array}$ & $\begin{array}{l}\text { Upper } \\
\text { bound }\end{array}$ & & \\
\hline AP Diameter at apex (a) & 60 & 6.25 & 1.336 & 0.172 & 5.9 & 6.6 & 3 & 9 \\
\hline Transverse width at base (b) & 60 & 15.68 & 3.017 & 0.389 & 14.9 & 16.46 & 9 & 25 \\
\hline Length of Hiatus(c) & 60 & 28.6 & 11.738 & 1.515 & 25.57 & 31.63 & 7 & 59 \\
\hline Distance from Apex to S2 foramina (d) & 60 & 26.97 & 11.443 & 1.477 & 24.01 & 29.92 & 0 & 46 \\
\hline Length of Hiatus+ Distance from Apex to S2 foramina (e) & 60 & 55.57 & 9.814 & 1.267 & 53.03 & 58.1 & 31 & 77 \\
\hline Distance from upper border of S1 to Apex of sacral hiatus (f) & 60 & 72.42 & 13.217 & 1.706 & 69 & 75.83 & 43 & 96 \\
\hline Base of the triangle $(\mathrm{A})$ & 60 & 62.07 & 4.751 & 0.613 & 60.84 & 63.29 & 52 & 73 \\
\hline $\begin{array}{l}\text { Distance between right superolateral sacral crest \& sacral } \\
\text { apex(B) }\end{array}$ & 60 & 57.18 & 9.304 & 1.201 & 54.78 & 59.59 & 37 & 76 \\
\hline $\begin{array}{l}\text { Distance between left superolateral sacral crest \& sacral } \\
\operatorname{apex(C)}\end{array}$ & 60 & 56.93 & 9.259 & 1.195 & 54.54 & 59.33 & 37 & 76 \\
\hline Angles between the lines A\&B & 60 & 55.78 & 6.3732 & 0.8228 & 54.134 & 57.427 & 34.7 & 65.6 \\
\hline Angles between the lines A\&C & 60 & 56.143 & 6.3582 & 0.8208 & 54.501 & 57.786 & 34.7 & 68.4 \\
\hline
\end{tabular}

The above table shows eleven parameters of the sacral hiatus in consolidated form. 


\section{DISCUSSION}

Nagar S.K noted various shapes of sacral hiatus, most common being Inverted ' $U$ ' (41.5\%) \& Inverted ' $V$ ' (27.0\%)[7]. In the present study also the shapes of sacral hiatus were variable most common being Elongated (33.3\%) which has not been reported in earlier studies followed by Irregular (23.3\%), Inverted 'U' $(23.3 \%)$, Inverted ' $V$ ' (13.3\%), Bifid (3.3\%) \& Dumbbell (3.3\%).

In the present study the apex of sacral hiatus was seen most commonly (51.7\%) at the level of $4^{\text {th }}$ sacral vertebra. Standard textbooks state that the apex of sacral hiatus is present at the level of $4^{\text {th }}$ sacral vertebra[2]. Various studies have shown similar results namely Vinod Kumar et al reported in his series that the apex of sacral hiatus was most commonly (76.23\%) present against $4^{\text {th }}$ sacral segment [8], Nagar S.K noted apex of sacral hiatus at S4 level in $55.9 \%$ cases[7], Sekiguchi $M$ et al noted the apex of sacral hiatus at $\$ 4$ level in $64 \%$ cases[5]. All studies including the present study noted that location of apex of sacral hiatus can vary from upper end of S2 to lower part of S5.

Cognizance of vertebral level of apex of $\mathrm{SH}$ is critical, as higher level may be risky because of closeness of dura mater which end at S2. Hence, there are increased possibilities of dural puncture if the apex of SH is situated at S2 or S3. Further, while determining the length of needle during CEB the level of apex of $\mathrm{SH}$ is exceedingly significant as lower level of apex needs long needle during CEB [9].

The base of the sacral hiatus was seen at the level of S5 vertebra in $66.7 \%$ sacra similar to Nagar S.K [7], 72.6\% and Vinod Kumar et al $83.17 \%$ [8]. It extended to coccyx in $33.3 \%$ similar to Nagar S.K , 16.3\% [7] .These sacra had coccygeal ankylosis.

During CEB, needle should be inserted at the base of $\mathrm{SH}$ to minimize the complications arising from variable levels of apex [10].

The antero posterior diameter of sacral canal at apex of sacral hiatus is important as it should be sufficiently large to admit a needle. Various diameters lead subcutaneous deposition of anaesthetic drug[10]. In the present study, the antero posterior diameter ranged from 3 to $9 \mathrm{~mm}$ with a mean of $6.25 \mathrm{~mm}$. Mean diameters reported by various workers are similar. Trotter et al , $5.3 \mathrm{~mm}$ (range of 0-11 mm) [11], Lanier et al ,6.1 $\pm 0.2 \mathrm{~mm}$ [12], Trotter et al , $5 \mathrm{~mm}$ in whites and $6 \mathrm{~mm}$ in Negro groups[13] , Vinod kumar et al , 4.8mm [8], Sekiguchi $M$ et al , $6.0 \pm 1.19 \mathrm{~mm}$ [5], and Nagar S.K $4.88 \mathrm{~mm}$ (range of 2-14 mm) [7]. In the present study, sacra has antero posterior diameter of sacral canal at apex of less than $3 \mathrm{~mm}$ which is lesser (3.33\%) than the earlier studies namely Trotter et al who reported $5 \%$ cases with 0-2 $\mathrm{mm}$ diameter[13], Trotter et al $4 \%$ sacra with diameter $0-2 \mathrm{~mm}[11]$, Nagar S.K $15.6 \%$ sacra with diameter 0-3 $\mathrm{mm}$ [7], while Lanier et al found no case with diameter less than $3 \mathrm{~mm}[12]$.

The width of base of sacral hiatus varied from 9-25 mm with a mean of $15.68 \mathrm{~mm}$ and in $51.66 \%$ cases it was $16-20 \mathrm{~mm}$. This was almost similar to earlier studies like Trotter et al who noted the width at base to vary from 7-26 mm with mean of $17 \mathrm{~mm}[11]$, Lanier et al , who reported mean width at base to be $19.3 \pm 0.3 \mathrm{~mm}$ [12] and Vinod Kumar et al who reported $5-20 \mathrm{~mm}$ (1.3 $\mathrm{mm}$ in mean) and 8-18 $\mathrm{mm}(1.25 \mathrm{~mm}$ in mean) in male and female sacra of his series[8]. Sekiguchi $M$ et al have reported a lower figure of $10.2 \pm 0.35 \mathrm{~mm}$ [5]. However, this may be because they note the average distance between sacral cornua.

Senoglu and colleagues found the distance between the sacral cornua 17.47 (7-28) mm greater than and the depth of the sacral hiatus 4.46 (1-7) $\mathrm{mm}$ [5] slightly lesser than those measured in our study [15.68 (9-25) $\mathrm{mm}$ and 6.25 (3-9) $\mathrm{mm}$ respectively]

The length of the sacral hiatus varied from 7-59 $\mathrm{mm}$ and in about $30 \%$ cases it was $21-30 \mathrm{~mm}$ in the present study. Vinod Kumar et al observed mean length of hiatus as $20 \mathrm{~mm}$ in males \& 18.9 $\mathrm{mm}$ in females[8]. Trotter et al have reported hiatal length as $24.8 \mathrm{~mm}$ in American males and $19.8 \mathrm{~mm}$ in females[13]. Similar results were noted by earlier studies of Trotter et al in which the length of hiatus varied from $0-60 \mathrm{~mm}$ with a mean of $22.5 \mathrm{~mm}$ [11] \& Lanier et al, mean length of hiatus being $25.3 \mathrm{~mm} \pm 9$ [12]. As the dural sac terminates around the level of S2, the distances from the apex and base of the sacral hiatus to the level of S2 foramina were also 
measured (in relation to the risk of dural puncture). In the present study the distance between the S2 foramen and the apex of the sacral hiatus was $26.97 \mathrm{~mm}$ on average(range 0-46 $\mathrm{mm}$ ) and the distance to the base of the sacral hiatus was $55.57 \mathrm{~mm}$ on average (range 31-77 mm). The distance from upper border of S1 to sacral apex varied from 43-96 $\mathrm{mm}$ with a mean value of $72.42 \mathrm{~mm}$.

There was complete agenesis of dorsal bony wall of sacral canal in 1 case in the present study. This is similar to that reported by previous workers namely Nagar S.K $1.5 \%$, [7]Trotter et al 1.8\% [11] and Vinod Kumar et al $1.49 \%$ [8].

Since the posterior superior iliac spines which are readily palpable on the body surface of a patient impose on the superolateral crest of the sacrum and the later points were used as landmarks forming the base of a sacral triangle.

The average distance between the two superolateral crests (the base of the triangle) in the present study was $62.07 \mathrm{~mm}$ (range $52-73 \mathrm{~mm}$ ) which is lesser than reported by Senoglu.N $66.51 \mathrm{~mm}$ (range 51-79.5 mm) [5].

The mean distance between the right superolateral sacral crests and the sacral apex in the present study was $57.18 \mathrm{~mm}$ (range 37$76 \mathrm{~mm}$ ) which is lesser than reported by Senoglu.N 67.10 (range 42.1-89 mm) [5].

The mean distance between the left superolateral sacral crest and the sacral apex in the present study was $56.93 \mathrm{~mm}$ (range $37-76 \mathrm{~mm}$ ) which is lesser than reported by Senoglu.N 67.53 $\mathrm{mm}$ (range 46-88.1 $\mathrm{mm}$ ) [5].

In addition to these measurements we measured the angles between the margins of the triangle formed by the two superolateral sacral crests and the sacral hiatus. The angle between the lines formed by the base of the sacral triangle and the apex of the sacral hiatus in the present study was 55.780 degree (range 34.7-65.6 degree) on the right side which is lesser than reported by Senoglu.N 61.89 degree (range50-70 degree) and 56.143 degree (range 34.7- 68.4 degree) on the left which is lesser than reported by Senoglu.N 61.22 degree (range 50-70 degree) [5]. We observed lesser values of angles between the base of the sacral triangle and apex of sacral hiatus when compared to the findings of Senoglu $\mathrm{N}$ et al. So, in Indians we recommend that slightly less angulations should be taken to locate the $\mathrm{SH}$.

To recognise the caudal epidural space the most commonly used technique is based on feeling the 'pop' on piercing the sacrococcygeal membrane, after the ascertainment of sacral hiatus by palpating the sacral cornua. By some investigators a failure rate of $25 \%$ has been stated. Even for experienced clinicians it is not always possible for the identification of the caudal epidural space and anatomical variation might be an influence. In the success of CEB the apex of the sacral hiatus is an essential bony landmark but it might be hard to palpate, especially in obese patients. Hence other important anatomical landmarks such as the sacral triangle formed between the posterior superior iliac spines and the apex of sacral hiatus might be of use. Our measurements reveal this to be an equilateral triangle. This practical guide will lead to the detection of the sacral hiatus easily and increase the success rate of CEB. If the sacral hiatus cannot be identified accurately it will be difficult to pass the needle into the sacral canal.

\section{CONCLUSION}

Though CEB has a wide scope of clinical applications, especially in adults sometimes it is hard to define the anatomical location of the sacral hiatus as well as the caudal epidural space. The ascertainment of the landmarks by the clinician allows the sacral hiatus to be determined and thus increase the successful outcome of CEB. As observed by various authors the success $\&$ reliability of caudal epidural anaesthesia depends upon anatomical variants of sacral hiatus

In the light of these data we believe, that in order to minimize the frequency of dural puncture and other feasible complications in adults, the needle should be introduced only a few millimetres after piercing the sacrococcygeal membrane.

To conclude, there is invariability in the anatomical structure of the sacrum, particularly the sacral hiatus. Nevertheless, we believe that the equilateral character of the sacral triangle formed connecting the two posterior superior 
iliac spines and the apex of the sacral hiatus will be practical advantage to the clinician in ascertaining the location of the sacral hiatus during CEB.

\section{Conflicts of Interests: None}

\section{REFERENCES}

[1]. Keith L.Moore. 398; 451; 461. Clinically oriented Anatomy. $6^{\text {th }}$ edition: Lippincott Williams \& Wilkins, Baltimore, 2009.

[2]. Susan Standring. In Gray's Anatomy.724-725; 760761. The Anatomical Basis of Clinical Practice. Churchill Livingstone, London, 2008.

[3]. Richard S.Snell. 326; 872. Clinical Anatomy by Regions. $8^{\text {th }}$ edition: Lippincott Williams $\&$ Wilkins, Baltimore, 2008.

[4]. Edwards WB,Hingson RA. Continuous caudal anaesthesia in obstetrics. American journal of surgery 1942;57;459-464.

[5]. Sekiguchi M, Yabuki S, Saton K, Kikuchi S. An anatomical study of the sacral hiatus: a basis for successful caudal epidural block. Clin.J.Pain. 2004; 20(1):51-54.

[6]. Mourgela S, Sakellaropoulos A, Anagnostopoulou S, Wamke JP. The dimensions of the sacral spinal canal in thecaloscopy: a morphometric MRI study. Neuroanatomy. 2009;8(1):1-3.
[7]. Nagar S.K. A study of sacral hiatus in dry human sacra:J.Anat.Soc.India. 2004; 53(2)18-21.

[8]. Vinod Kumar,Pandey SN,Bajpai RN, Jain PN, Longia GS. Morphometrical study of sacral hiatus. Journal of Anatomical Society of India.1992;41(1):7-13.

[9]. Aggarwal A,Aggarwal A, Harjeet, Sahni D. Morphometry of sacral hiatus and its clinical relevance in caudal epidural block. Surg Radiol Anat 2009 Jul 4.

[10]. Mustafa MS, mahmoud OM, El Raouf HH, Atef HM. Morphometric study of sacral hiatus in adult human Egyptian sacra: Their significance in caudal epidural anaesthesia. Saudi Journal of Anaesthesia. 2012;6(4):350-57.

[11]. Trotter M, Letterman GS. Variations of the female sacrum; Their significance in continuous caudal analgesia. Surgical Gynaecology \& Obstetrics.1944;78(4):419-424.

[12]. Lanier VS, McKnight HE, Trotter M. Caudal analgesia: An experimental and anatomical study. America journal of Obstetrics and Gynaecology. 1944;47(5):633-641.

[13]. Trotter M. Variations of the scaral canal; Their significance in the administration of caudal analgesia.1947;26(5):192-202.

How to cite this article:

Susie Jeyalyn David MORPHOMETRIC MEASUREMENTS OF SACRAL HIATUS IN SOUTH INDIAN DRY HUMAN SACRA FOR SAFE CAUDAL EPIDURAL BLOCK. Int J Anat Res 2019;7(3.3):6911-6917. DOI: 10.16965/ijar.2019.254 